\title{
Gelir Eşitsizliği ve Doğrudan Yabancı Sermaye Yatırımları İlişkisi: Panel Veri Analizi
}

\section{Income Inequality and Foreign Direct Investment Relationship: A Panel Data Analysis}

Can KARABIYIK, Celal Bayar Üniversitesi, Türkiye, c_karabiyik@hotmail.com İlkay DİLBER, Celal Bayar Üniversitesi, ilkay.dilber@cbu.edu.tr

Öz:Bu çalışmada, 1970-2008 yilların içeren dönemde az gelişmiş, gelişmekte olan ve sanayileşmiş 50 ülke için doğrudan yabancı sermaye yatırımları ile gelir dağılımı eşitsizliği arasındaki etkileşim hem ampirik hem de teorik açıdan makroekonomik boyutta panel veri analizi kullanılarak incelenmiştir. Yatay kesit bağımlıllğ̆ sinaması için CDLM test, durağanlığın araştırılması için CADF birim kök testi ve değişkenler arasındaki iliş̧kinin varlığı ayrıca niteliğinin incelenmesi için CCE ve EKK tahmincilerinin kullanıldığı uygulamada, doğrudan yabancı sermaye yatırımlarının gelir dağılımı eşitsizliğini iyileştirmeye yardımcı olduğu diğer yandan ise ekonomik büyüme vasitasıyla arttırılan milli gelirin adil bir şekilde dağıtılamadı̆̆ sonucuna ulaşılmıştır.

Anahtar Sözcükler: Gelir Dă̆ılımı, Gini Katsayısı, Doğrudan Yabancı Sermaye Yatırımları, Panel Veri Analizi, Ekonomik Büyüme.

Abstract: In this study, interaction between foreign direct investment and income inequality is investigated in macroeconomic extent from both empirical and theoretical perspectives for 50 less developed, developing and developed countries between 1970 and 2008 by employing panel data methodology. It is found that in the empirical analysis in which CDLM test is used to examine cross-section dependence, CADF unit root test is utilized to check stationarity and CCE, OLS estimators are applied to analyze existence and also characteristics of relationship between variables, foreign direct investment recruits to ameliorate income inequality while increased national income through economic growth are not able to distributed fairly.

Keywords: Income Distribution, Gini Coefficient, Foreign Direct Investment, Panel Data Analysis, Economic Growth

\section{Giriş}

Küreselleşmenin hızla ilerlediği çağımızda doğrudan yabancı sermaye yatırımları ve çok uluslu şirketlerin özellikle gelişmekte olan ülke ekonomileri üzerindeki etkileri nadiren tartışılmaktadır. Bu araştırma çok uluslu şirketler tarafından gerçekleştirilen doğrudan yabancı sermaye yatırımlarının önemli bir ekonomik kalkınma göstergesi olan gelir dağılımı eşitsizliği üzerindeki etkisini incelemeyi ve bu iki olgu arasında herhangi bir ilişkinin mevcut olup olmadığını belirleyerek politika yapıcılara daha yüksek refah düzeyinde bir ekonomik sistem oluşturma yolunda fikir vermeyi amaçlamaktadır.

Dünya iktisadi tarihi göz önüne alındığında pek çok gelişmekte olan ülke gerek varlığını sürdürebilmek amacıyla zaruri olan kaynakları elde edebilmek gerek de sanayileşmiş ülkelerin küresel sermaye ve şirketler üzerindeki etkisi sebebiyle sanayileşmiş ekonomilere bağımlı hale gelmiştir (Seyrek 2002). Ancak, özellikle geçtiğimiz 30 yılda dünya ekonomisi ticaret ve sermaye piyasalarının liberalleșmesiyle, teknolojik ilerlemeler vasıtasıyla, dıș ticaret bariyerlerinin yerle bir edilmesiyle ve firmaların artan bir şekilde uluslararasılaşmasıyla küreselleşmektedir. Bu süreçte, gelişmekte olan ülkeler dünya ekonomisinde önem kazanarak uluslararası ticarette ve küresel piyasada önemli aktörler haline gelmişlerdir. Gelişmekte olan ekonomilerin uluslararası ticaret ve küresel piyasalar üzerindeki artan etkisi sonucu yabancı sermaye yoğun bir şekilde, özellikle doğrudan yabancı sermaye yatırımı olarak çok uluslu şirketler vasıtasıyla söz konusu ülkelere doğru harekete geçmiştir. Bu çalışmada doğrudan yabancı sermaye yatırımı hareketlenmelerinin gelir dağılımı eşitsizliği üzerinde yaratmış olduğu etki 50 ülkeyi içeren ve 1970 ile 2008 yılları arasındaki dönemi kapsayan oldukça geniş bir veri seti ile panel veri analizi kullanılarak incelenecektir. Gelir dağılımı eşitsizliğini konu alan ampirik çalışmalarda öne çıkan başlıca sorunlardan birisi olan veri yetersizliği, Birleşmiş Milletler Endüstriyel Kalkınma Organizasyonu (UTIP- UNIDO) öncülüğünde gerçekleştirilen Texas Üniversitesi Eşitsizlik Projesi kapsamında oluşturulan 149 ülkeye ait gelir dağılımı eşitsizliği (GINI) değerlerinin yer aldığı yeni bir veri setinin kullanımıyla aşılmaya çalışılmıştır. Araştırmada ilk olarak doğrudan yabancı sermaye yatırımları ve gelir dağılımı eşitsizliği ilişkisi ile ilgili olan teorik çerçeve ele alınacak olup sonraki bölümde ampirik analizde kullanılmış olan veri seti ve metot tanıtılacaktır. Son olarak ise araştırma bulguları açılanacak ve sonuç bölümüne yer verilecektir.

\section{Teorik Çerçeve}

Doğrudan yabancı sermaye yatırımları ve gelir dağılımı eşitsizliği ilişkisi için yapılacak ampirik çalışmalara yön verebilecek herhangi bir teorik çerçeve hakkında fikir birliğine ulaşılamamıştır. Ancak günümüzde pek çok kalkınma iktisatçısı ve uluslararası ekonomik kuruluş doğrudan yabancı sermaye yatırımlarının, yatırımı alan ülkenin ekonomik büyümesine ve 
kalkınmasına modern teknolojilerin, yönetim becerilerinin ve beşeri sermayenin transferi vasıtasıyla katkıda bulunabileceğine inanmaktadır (Tsai 1995). Doğrudan yabancı sermaye yatırımlarının, yatırımı alan ülke ekonomisinin büyüme ve verimlilik değerleri üzerinde olumlu etkiye sahip olduğu kabul edilmektedir ancak gelir dağılımı eşitliği konusu genellikle görmezden gelinmektedir (Figini and Görg 2011). Doğrudan yabancı sermaye yatırımları sermaye kıtlığını engellemesi, toplam faktör verimliliğini arttırması, dış ticareti canlandırması gibi pek çok olumlu yönüyle cazip görünmektedir ancak bu faydalarına rağmen bazı ekonomilerde kısıtlanmaktadır (Doğan, Shahınpour, and Aghapour 2013). Bu kısıtlamaların sebebi ise doğrudan yabancı sermaye yatırımlarının avantajlarıyla birlikte ortaya çıkan dezavantajları olmaktadır. Doğrudan yabancı sermaye yatırımlarının, gelir dağılımı üzerinde de bozucu etkileri ortaya çıkabilmektedir. Örneğin küreselleşme sonucu emek talebiyle beraber daha esnek bir hale gelen iş gücü talebi ile iş gücünün pazarlık gücü ciddi oranda azalmakta ve sonuç olarak ülkeler arasında ciddi ücret farklılıkları ortaya çıkabilmektedir (Rodrik 1997). Ayrıca büyük ölçekli uluslararası firmalar tarafından gerçekleştirilen doğrudan yabancı sermaye yatırımları orantısız rekabet vasıtasıyla küçük yerli yatırımcıları piyasanın dışına atarak iç piyasada bozulmalara ve sosyal refahı azaltan oligopolcü yapılara yol açmaktadır (Gedikli 2011).

Çeşitli ekonomilerin sürdürülebilir ekonomik büyümeye erişmek için kullanmış oldukları içe dönük ve dışa dönük kalkınma stratejileri birer büyüme patikası teşkil etmekte ve birbirlerinden oldukça farklı bir görünüm çizmektedirler. İçe dönük kalkınma, iç endüstrilerin inşa edilmesi ve geliştirilmesine odaklanmaktadır. Bu strateji çerçevesinde, Negishi (2014) tarafından yeni gelişmekte olan ve henüz rekabet gücü olmayan endüstriler olarak tanımlanan bebek endüstrilerin yüksek ticaret bariyerleri ile küresel rekabetten korunarak bu sektörlerde karşılaştırmalı üstünlük kazanılması amaçlanmaktadır. Doğrudan yabancı sermaye yatırımlarına ancak çok düşük düzeylerde izin verilmektedir. Ancak bu stratejinin etkin kaynak dağılımını sağlayamaması, düşük seviyedeki doğrudan yabancı sermaye yatırımlarının bilgi ve teknoloji transferini yavaşlatması, ekonomik büyüme oranlarının artmasına engel olarak hükümetlerin düşük korumacılık politikaları uygulamalarına neden olmuştur. Dışa dönük stratejiler ise özünde içe dönük stratejinin tam tersini ifade etmektedir ve uluslararası ticarete odaklanmaktadır. Bu stratejiyi uygulayan ekonomiler ticaret bariyerlerini kaldırmakta ve yüksek düzeyde doğrudan yabancı sermaye yatırımlarını teşvik ederek teknoloji ve bilgi transferini arttırmayı bu suretle de ekonomiyi canlandırmayı amaçlamaktadır.

Stolper ve Samuelson (1941)'e göre serbest ticaret gelir dağılımını ülkede bol olan üretim faktörünün lehine, kıt olan üretim faktörünün ise aleyhine etkileyecektir. Bir başka deyişle genellikle emek yoğun üretim yapan az gelişmiş ve gelişmekte olan ülkeler serbest ticarete dahil olduklarında sahip oldukları milli gelir daha adaletli bir şekilde dağılacaktır. Ancak serbest ticaret özellikle Türkiye gibi gelişmekte olan ekonomilerde Stolper ve Samuelson (1941)'in iddia ettiği gibi daha adil bir gelir dağılımına değil, aksine gelir dağılımı eşitsizliğini arttırıcı bir etki ortaya çıkarmaktadır (Gökalp, Baldemir, and Akgün 2011).

Yapılacak olan doğrudan yabancı sermaye yatırımının yatay veya dikey olması da gelir dağılımı eşitsizliği bakımından önem taşımaktadır. Yatay doğrudan yabancı sermaye yatırımı aynı üretim tekniği ile aynı ürünlerin farklı ülkelerde üretilmesi olarak tanımlanırken, dikey doğrudan yabancı sermaye yatırımı ile üretim aşamalarının coğrafi olarak farklı parçalara ayırılarak maliyet avantajı elde edilmesini bir başka deyişle üretimin her aşamasının minimum maliyet öneren ülkede gerçekleştirilmesi olarak ifade edilmektedir (Protsenko 2004). Yatırım alan ülkedeki işgücüne erişimin göreli olarak ucuz olması, zengin kaynak ülkelerden doğrudan yabancı sermaye akışını teşvik ederek üretimin emek yoğun bölümlerini bu ülkelere kaydırarak dikey doğrudan yabancı sermaye yatırımına yol açacak böylelikle de nitelikli işgücünün gelirini arttırarak gelir dağılımını bozucu etki yapabilecektir (Herzer ve Nunnenkamp, 2011).

İktisat literatüründe doğrudan yabancı sermaye yatırımlarının gelir dağılımı eşitsizliği üzerindeki etkilerini açıklamaya yönelik birkaçı yukarıda da açıklanmış olan pek çok sav mevcuttur. Ancak genel olarak ele alındığında, modernizasyon ve bağımlılık kuramları olarak adlandırılan iki hipotez doğrudan yabancı sermaye yatırımlarının gelir dağılımı üzerindeki sonuçlarının açıklanması konusunda öne çıkmaktadırlar. Her ikisi hipotez de yabancı sermaye yatırımlarının kalkınma sürecindeki önemini vurgularken, yatırımı alan ülkenin gelir dağılımı eşitliği hakkında birbirlerinden oldukça farklı iddialarda bulunmaktadırlar (Tsai 1995).

Modernizasyon kuramı, yabancı ve yerli sermayeyi birbirlerinden farklı olarak ele almamaktadır. Sermayenin yabancı veya yerli olması fark etmeksizin daha büyük bir sermaye stoku ekonominin daha yüksek oranlarda büyümesine olanak sağlayacak ve toplumsal refah artacaktır. Modernizasyon kuramının gelir dağı̆lımı eşitsizliğine bakış açısı ise "Kuznets Eğrisi" yaklaşımıyla açıklanmaktadır. Bu yaklaşıma göre kalkınma sürecinin ilk aşamalarında gelir dağılımı eşitsizliği bozulurken, belirli bir seviyedeki kalkınma düzeyine ulaşıldığı andan itibaren gelir dağılımı daha adil bir şekilde gerçekleşecektir. Özetle, doğrudan yabancı sermaye yatırımları az gelişmiş ve gelişmekte olan ülkelerdeki sermaye yetersizliği sorunu giderecek ve bu ülkelerin beşeri sermayelerini teknoloji ve bilgi transferi vasıtasıyla iyileştirerek daha adil bir dağılıma olanak sağlayabilecektir.

Bağımlılık kuramı ise modernizasyon kuramının aksine doğrudan yabancı sermaye yatırımlarının gelir dağılımı üzerinde olumsuz etkiler yaratacağı iddiasındadır. Gelir dağılımı ilk aşamada Kuznets Eğrisi yaklaşımında ifade edildiği gibi kötüleşecek ancak daha sonraki aşamalarda da iyileşme eğiliminde olmayacaktır. Yabancı yatırımların ekonomiye girmesiyle sektörler arası ikililik meydana gelecek, uluslararası sektörlerde istihdam edilmiş olan iş gücü toplumun geneline göre yüksek geliri olan yeni bir elit sınıf oluşturacaktır. Eşitsizleşme eğiliminde olan gelir dağılımı hükümetlerin ülkeye 
sermaye çekmeye yönelik politikaları sebebiyle daha da kötüleşecektir. Bunlara ilaveten ölçek ekonomilerinden faydalanmakta olan büyük boyuttaki çok uluslu şirketler rekabet avantajı olmayan küçük ve orta ölçekli yerli firmaları piyasa dışına iterek gelir dağılımının daha da eşitsiz bir hale gelmesine neden olacaktır. Bağımlılık Kuramcıları'na göre modernizasyon hipotezi sömürü düzenini meşrulaştırmak için ortaya atılmıştır (Ongan 2004).

\section{Literatür Taraması}

Tsai (1995), doğrudan yabancı sermaye yatırımlarının gelir dağılımı eşitsizliği üzerindeki etkisini 119 adet ülkenin 1993 ve 2003 arasındaki verilerini kullanarak incelemiştir. Yapılan araştırmada coğrafi kukla değişkenler yardımıyla ülkeler karşılaştırılarak sonuçlar ülkelerin ekonomik durumlarına göre sınıflandırılmıştır. Yapılan sınıflandırmalara dayanılarak söz konusu ilişkinin bölgelere ve ülkelere göre farklılık gösterdiği ifade edilmektedir. Özellikle az gelişmiş ülkelerde doğrudan yabancı sermaye yatırımlarının gelir dağılımı eşitsizliğini arttırdığı sonucuna ulaşılmıştır.

Aitken, Harrison, ve Lipsey (1996), doğrudan yabancı sermaye yatırımları ve gelir dağılımı eşitsizliği ilişkisini Meksika, Venezüella ve ABD ekonomileri için sektörlere ait verileri kullanarak analiz etmişlerdir. Araştırma bulgularına göre, örneklem için seçilen ülkelerin birbirinden oldukça farklı iktisadi koşulları ve kalkınmışlık düzeylerinin mevcudiyetine rağmen doğrudan yabancı sermaye yatırımları ve ücretler arasında istatistiksel olarak oldukça güçlü pozitif ilişkiye rastlanmıştır.

(Mah 2002), dış ticaret hacmi ve doğrudan yabancı sermaye yatırımlarının Gini katsayısı üzerindeki etkisini Kore Ekonomisi için söz konusu değişkenlerin 1975 ile 1995 yılları arasındaki değerlerini kullanarak incelemişlerdir. Elde edilen analiz bulgularına göre, kullanılan değişkenlerin birinci dereceden eş-bütünleşik olduğu ve dış ticaret hacmi ile doğrudan yabancı sermaye yatırımı değerleri yükseldikçe Gini Katsayısının da yükseldiği sonucuna varılmıştır. Bir başka deyişle Kore'de dış ticaret hacmi ve doğrudan yabancı sermaye yatırımlarının artması gelir dağılımı üzerinde bozucu etki doğurmaktadır.

Ongan (2004), gelir dağılımı eşitsizliği ve doğrudan yabancı sermaye yatırımları arasındaki ilişkiyi 26 ülke için yatay kesit analizi yöntemi ile incelemiştir. Elde edilen analiz sonuçlarına göre doğrudan yabancı sermaye yatırımları gelir dağılımını daha eşitsiz bir hale getirmektedir. Bir başka deyişle analiz sonuçları bağımlılık hipotezini desteklemektedir.

Sylwester (2005), az gelişmiş ülkelerde doğrudan yabancı sermaye yatırımlarının ekonomik büyüme ve gelir dağılımı eşitsizliği üzerindeki etkisini incelediği araştırmasında 1970 ile 1989 yılları arasını kapsayan bir panel veri seti kullanmıştır. Analiz bulguları doğrudan yabancı sermaye yatırımlarının ekonomik büyümeyi olumlu yönde etkilediğini ve bu tip ülkelerde doğrudan yabancı sermaye yatırımları ile gelir dağılımı eşitsizliği arasında anlamlı bir ilişkinin var olmadığını işaret etmektedir.

119 ülkeyi kapsayan ve 1970 ile 1999 yılları aralığını içeren bir panel veri seti kullanılarak gerçekleştirilen bir diğer araştırmada, Basu ve Guariglia (2007) yabancı sermayenin teşvik edilerek iç ekonomiye doğrudan yatırımlar yoluyla çekilmesinin gelir dağılımı eşitsizliğini arttırdığına dair bulgular elde etmişlerdir.

Jensen ve Rosas (2007), çokuluslu şirketlerin doğrudan yatırımlarının, Meksika eyaletlerindeki gelir dağılımı üzerindeki etkisini 1990 ve 2000 yılları arası için bölgesel olarak incelemiş̧lerdir. Elde ettikleri analiz bulgularına göre, eyaletlerin üçte ikisinde doğrudan yabancı sermaye yatırımları gelirin daha adil bir şekilde dağıtılmasına yardımcı olmaktadır.

Figini and Görg (2011), doğrudan yabancı sermaye yatırımları ile ücret eşitsizliği arasındaki ilişkiyi çeşitli kalkınma seviyelerinden 100'ü aşkın ekonominin 1980 ile 2002 yılları arasını kapsayan bir veri seti ile incelemişlerdir. Araştırmalarında, doğrudan yabancı sermaye yatırımlarının gelir dağılımı üzerindeki etkisinin ülkenin kalkınmışlık seviyesine göre farklılık gösterdiğine dair ampirik bulgular elde etmişlerdir. Çalışma sonuçlarına göre gelişmekte olan ülkelerde doğrudan yabancı sermaye yatırımları ile ücret eşitsizliği arasında doğrusal olmayan pozitif ilişki mevcut iken gelişmiş ülkelerde her iki değişken arasında negatif yönlü ilişki saptanmıştır.

Gökalp, Baldemir, and Akgün (2011) Türkiye'de 1980-2001 yılları arasında gelirin daha eşit dağılmadını, aksine gelir dağılımı eşitsizliğinin arttığını iddia etmektedirler. Stolper-Samuelson teoremine tezat teşkil eden araştırmalarına göre, bu olumsuz etkinin altında yatan sebebi doğrudan yabancı sermaye yatırımlarının vasıflı iş gücü talebini arttırması ve dolayısıyla bu kesimde ücretlerin yükselmesi olarak göstermektedirler.

Herzer ve Nunnenkamp (2011), tarafından gerçekleştirilen araştırmada doğrudan yabancı yatırım ve gelir eşitsizliği ilişkisi 10 Avrupa ülkesi için eş-bütünleşme ve nedensellik metotları kullanılarak 1980 ve 2000 yılları arasında kısa ve uzun dönem için ayrı ayrı incelenmiştir. Herzer ve Nunnenkamp (2011)'e göre doğrudan yabancı sermaye yatırımları gelir dağılımını kısa dönemde adaletsizleştirirken, uzun dönemde ise ortalamada iyileştirmektedir. Araştırma bulguları modernizasyon dolayısıyla da Kuznets Eğrisi hipotezlerini destekler niteliktedir. Öte yandan gelir dağılımı eşitsizliği ve doğrudan yabancı sermaye yatırımları arasında çift yönlü nedensel ilişki bulunduğunu iddia etmektedirler.

Chıntrakarn, Herzer, ve Nunnenkamp (2012) Amerika Birleşik Devletleri'nin 48 eyaletindeki gelir dağılımı ve doğrudan yabancı sermaye yatırımları ilişkisini panel veri analizi yöntemi yardımıyla incelemişlerdir. Yapılan analize göre; doğrudan yabancı sermaye yatırımlarının gelir dağılımını kısa dönemde düşük anlamlılık düzeyinde negatif yönlü, uzun 
dönemde ise oldukça anlamlı ve yine negatif yönlü olarak etkilediği sonucuna varmışlardır. Bir başka deyişle ABD vatandaşlarının gelirleri arasındaki uçurum uzun dönemde doğrudan yabancı sermaye yatırımları vasıtasıyla kapanmaktadır. Ancak Chıntrakarn, Herzer, ve Nunnenkamp (2012) sonuçlarda kayda değer heterojenlik olduğunu ve bu bulguların tüm ABD ekonomisine genellenemeyeceğini ifade etmektedirler.

Sarisoy ve Koc (2012), az gelişmiş ve gelişmekte olan 40 ülke için oluşturdukları 1980-2008 dönemini içeren panel veri seti ile doğrudan yabancı sermaye yatırımlarının yoksulluğu ne şekilde etkilediğini ekonomilerin \%10’luk gelir dağılım dilimlerini kullanılarak incelemişlerdir. Araştırma bulgularına göre, doğrudan yabancı sermaye yatırımlarının tüm gelir gruplarını olumlu etkilemesine rağmen gelirdeki en büyük artışın üst gelir gruplarında gözlemlenmesinden dolayı gelir dağılımının iyileşmesine katkı sağlanamamaktadır.

Doğan, Shahınpour, ve Aghapour (2013), İran ekonomisinin 1970 ve 2010 yılları arasındaki dönemini ele alarak yaptıkları araştırmada doğrudan yabancı sermaye yatırımlarındaki bir artışın gelir dağılımı eşitsizliğini iyileştirmede önemli rol oynadığını tespit etmiştir. Bu araştırmaya ait bulgular modernizasyon hipotezini desteklemektedir.

Ucal (2014), gelişmekte olan 26 ülke için yoksulluk ve doğrudan yabancı sermaye yatırımları arasındaki ilişkiyi, oluşturduğu 1990 ve 2009 yılları arasını kapsayan 29 yıllık panel veri seti ile incelemiş ve doğrudan yabancı sermaye yatırımları ile yoksulluk arasında istatistiksel olarak anlamlı negatif ilişki saptamıştır. Ucal (2014)’e göre doğrudan yabancı sermaye yatırımları yoksulluğu azaltmaktadır.

Erkal, Akıncı, ve Yılmaz (2015), 1998 - 2010 dönemi ekonomik büyüme, gelir dağılımı eşitsizliği ve yoksulluk ilişkilerini 11 ülke için panel ver analizi metoduyla incelemişlerdir ve vekil değişken olarak kullandıkları doğrudan yabancı sermaye yatırımlarındaki bir artışın ekonomik büyümeyi arttırdığı ve yoksulluğu azalttığını iddia etmektedirler.

Meksika'da gelir dağılımı ile doğrudan yabancı sermaye yatırımları arasındaki ilişkiyi analiz eden bir başka çalışma ise Feenstra ve Hanson (1997) tarafından nitelikli işgücünün nispi ücretleri kullanılarak 1975 - 1988 dönemini kapsayacak şekilde gerçekleştirilmiştir ve ücret farklılığı oluşturan nitelikli işgücü ücretlerindeki artışların \% 050 'sinin doğrudan yabancı yatırımlarından kaynaklandığı sonucuna ulaşılmıştır.

\section{Veri, Yöntem ve Analiz Bulguları}

Bu araştırmada 50 adet az gelişmiş, gelişmekte olan ve gelişmiş ülkenin 1970 ve 2008 y1lları arasındaki döneme ait Gini katsayısı, doğrudan yabancı sermaye yatırımları ve gayri safi yurtiçi hasıla değişkenleri kullanılmıştır. Araştırma, tercih edilen değişkenler itibariyle Mah (2002) ve Sylwester (2005) benzerlik göstermektedir.

Gelir dağılımı konusunun iktisatçıların üzerinde titizlikle durduğu bir araştırma alanı olmasına rağmen özellikle az gelişmiş ve gelişmekte olan ülkeler için yeterli veri bulunamaması bu alanda yapılan çalışmaların genellikle gelişmiş ve sanayileşmiş ülke ekonomileri için yapılmasına sebebiyet vermektedir (Elveren 2013). Bu sorunun aşılabilmesi amacıyla Birleşmiş Milletler Endüstriyel Kalkınma Organizasyonu (UTIP- UNIDO) öncülüğünde gerçekleştirilen Texas Üniversitesi Eşitsizlik Projesi kapsamında 149 ülkeye ait gelir dağılımı eşitsizliği (GINI) değerlerinin yer aldığı kapsamlı bir veri seti oluşturulmuştur. Bu çalışmada da kullanılan bu değerler, imalat sanayindeki ücret farklılıklarının Theil endeksi ile hesaplanması ve Gini katsayısı formuna dönüştürülmesi ile meydana getirilmiştir. Doğrudan yabancı sermaye yatırımları (FDI) verileri ise Birleşmiş Milletler Ticaret ve Kalkınma Konferansı Veri tabanından (UNCTADSTAT) elde edilmiştir. Milli gelir ile gelir dağılımı eşitsizliği arasında eğrisel bir ilişki mevcuttur ve milli gelir, gelir dağılımının belirleyicilerindendir (Crenshaw 1992). Bu sebeple modele gayri safi yurtiçi hasıla logaritması alınıp dahil edilerek ihmal edilmiş değişken sorununun giderilmesi amaçlanmıştır. Gayri safi yurtiçi hasıla (GSYİH) verileri ise Dünya Bankası'nın Dünya Kalkınma Göstergeleri (Worldbank WDI) veri tabanından alınmıştır.

Ampirik çalışmalarda kullanılan veri setlerinin yeterince büyük bir zaman dönemini kapsayamaması yapılan araştırmanın açıklayıcılığını kısıtlayan önemli bir unsur olarak ortaya çıkmaktadır ancak bu kısıt Baltagi (2005) tarafından zaman serileri ile yatay kesitlerin bir kombinasyonu olarak tanımlanan ve modele daha yüksek seviyede serbestlik derecesi, değişkenlik, etkinlik sağlayan panel veri analizi yönteminin kullanılmasıyla ortadan kaldırılabilmektedir. Araştırmada kullanılmış olan panel veri modeli aşağıdaki denklemde gösterilmektedir:

$$
G I N I_{i t}=\alpha+\beta_{1} F D I+\beta_{2} G S Y \dot{I} H+e_{i t}
$$

Veri setinde yer alan zaman serileri arasında yatay kesit bağımlılığının (YKB) var olması durumunda analiz sonuçları YKB'nin göz önünde bulundurulup bulundurulmamasından ciddi boyutta etkilenmektedir (Pesaran 2004). Sahte regresyon sorununun önüne geçilebilmesi amacıyla kullanılan birim kök testinin türü YKB'nin varlığına göre seçilmektedir. YKB’nin var olması durumunda YKB'yi dikkate almayan birim kök testlerinin kullanımı gerçekte durağan olan serilerin durağan olmadığına dair bulgular hatalı sunarak serinin farkının alınması suretiyle uzun dönemli iktisadi bilginin yok edilmesine sebep olabilmektedir. Bu sebeple ampirik çalışmadaki ilk adım YKB’nin test edilmesi olmaktadır. Kullanılacak olan YKB testi ise yatay kesit ve zaman boyutlarının göreli büyüklerine göre seçilmektedir. Kullanılan veri setindeki zaman boyutu yatay kesit boyutundan büyük olduğu durumda $(T>N)$ Breusch ve Pagan (1980) tarafindan geliştirilmiş olan $C_{2} M_{1}$ testi, her iki boyutun büyüklüğünün birbirine eşit olduğu durumda $(\mathrm{T}=\mathrm{N})$ Pesaran (2004) tarafından ortaya atılmış olan $\mathrm{CDLM}_{2}$ testi, yatay kesit boyutunun zaman boyutundan büyük olduğu $(\mathrm{T}<\mathrm{N})$ durumda ise Pesaran (2004) CDLM testi 
uygulanmaktadır. Bu çalışmada kullanılan veri setinde yatay kesit boyutu zaman boyutundan büyük olduğu için Pesaran (2004) CDLM testi kullanılacaktır. CDLM test istatistiği aşağıdaki denklem yardımıyla hesaplanmaktadır;

$$
C D L M=\sqrt{\frac{1}{N(N-1)}} \sum_{i=j}^{N-1} \sum_{j=i+1}^{N}\left(T \hat{\rho}_{i j}^{2}-1\right) \sim N(0,1)
$$

Yukarıdaki denklemin çözülmesi sonucu elde edilecek olan değer asimptotik olarak normal dağılmaktadır. Testin hipotezleri aşağıdaki gibi ifade edilmektedir;

$\mathrm{H}_{0}$ : Yatay kesitler arasında bağımlılık yoktur

Ha: Yatay kesitler arasında bağımlılık vardır

CDLM Testi kullanılarak Tablo 1'deki sonuçlar elde edilmiştir;

Tablo 1: Yatay Kesit Bağımlılığı Testi Sonuçları

\begin{tabular}{|l|l|l|}
\hline Değişken & CDLM test istatistiği & Olasilık değeri \\
\hline GINI & $-2,903$ & $0,002 * * *$ \\
\hline FDI & 6,293 & $0,000 * * *$ \\
\hline GSYİH & $-3,450$ & $0,000 * * *$ \\
\hline
\end{tabular}

*** \%1 anlamlılık düzeyinde anlaml

Tablo 1'deki bulgulara göre $\mathrm{H}_{0}$ hipotezi \%1 anlamlılık düzeyinde reddedilerek her üç değişken için de paneli oluşturan ekonomilerde yatay kesit bağımlılığı olduğu sonucuna ulaşılmıştır. Bir diğer deyişle, ekonomilerden birisince uygulanan politikaların etkileri yayılmakta ve diğer ülkeleri de etkilemektedir. Bu sebeple söz konusu ülkeler politika geliştirme sürecinde diğer ülkelerce yürürlüğe konulan politikaları da dikkate almalıdırlar.

YKB modelde kullanılan değişkenlerin durağanlığının test edilmesinde kullanılacak olan birim kök testlerinin seçilmesinde de belirleyici olmaktadır. YKB'na yol açan gözlenemeyen ortak stokastik trend, gözlenemeyen ortak faktörler, genel makroekonomik şoklar ve mekansal otokorelasyon gibi faktörlerin hatalı analiz sonuçlarına yol açmaması için YKB'yi dikkate alan birim kök testleri ve tahmincileri kullanılmalıdır. Modele dahil edilen değişkenlerde YKB mevcut olduğu için YKB'yi dikkate alan 2. Nesil birim kök testleri tercih edilmelidir çünkü 1. nesil birim kök testleri yatay kesitler arasında bağımlılık olmadığı varsayımına dayanmaktadır. Bu çalışmada YKB'nı dikkate alan Pesaran (2007) CADF testi kullanılarak serilerin durağanlığı araştırılmıştır. Durağanlık, bir zaman serisine ait olan ortalama ve varyans değerlerinin zaman boyunca sabit kalması ve zaman serisindeki iki faklı nokta arasındaki kovaryans değerinin bu iki nokta arasındaki mesafeye bağlı olması şeklinde tanımlanmaktadır (Gujarati 2009). CADF testi ADF regresyon denklemini, yatay kesit serilerinin birinci farklarının ve gecikmeli değerlerinin ortalamalarını alarak aşağıdaki formülde olduğu gibi hesaplamaktadır:

$$
\Delta y_{i, t}=a_{i}+\rho_{i} y_{i, t-1}+b_{i} \bar{y}_{t-1}+\sum_{j=0}^{p} c_{i j} \Delta \bar{y}_{t-1}+\sum_{j=1}^{p} d_{i j} \Delta y_{i, t-j}+e_{i, t}
$$

Yukarıdaki denklem CADF olarak isimlendirilmiştir ve denklemde yer alan $\bar{y}_{t}$ ve $\Delta \bar{y}_{t}$ değerleri aşağıdaki gibi gösterilmektedir:

$$
\begin{gathered}
\bar{y}_{t}=\frac{1}{N} \sum_{i=1}^{N} y_{i t} \\
\Delta \bar{y}_{t}=\frac{1}{N} \sum_{i=1}^{N} \Delta y_{i t}
\end{gathered}
$$

Pesaran (2007)'ye göre, yukarıdaki iki ifadenin yatay kesitsel ortalamaları gözlemlenemeyen bir ortak çarpanın göstergesi olarak modele ilave edilmektedir. CADF testi ile her bir yatay kesit için ayrı ayrı ve panelin geneli için birim kök testi yapılabilmektedir. Boş hipotezi seride birim kök olduğunu, alternatif hipotezi ise serinin durağan olduğunu ifade eden CADF testinin test istatistiği aşağıdaki gibi hesaplanmaktadır:

$$
\begin{gathered}
Y_{i, t}=\left(1-\emptyset_{i}\right) \mu_{i}+\emptyset_{i} y_{i, t-1}+u_{i, t} \quad i=1,2, \ldots, N \quad t=1,2, \ldots, T \\
u_{i, t}=\gamma_{t} f_{t}+\varepsilon_{i, t}
\end{gathered}
$$

Yukarıdaki denklemde yer alan $f_{t}$ ifadesi gözlenemeyen ortak faktörleri, $\varepsilon_{i, t}$ ise yatay kesit hata terimini ifade etmektedir. CADF testinin hipotezleri aşağıdaki gibi gösterilebilir:

$\mathrm{H}_{0:}$ Seri durağan değildir

$\mathrm{H}_{1}$ : Seri durağandır

Ayrıca yatay kesitlerin CADF test istatistiklerinin aritmetik ortalaması olan CIPS (Cross-Sectionally Augmented IPS) panel birim kök testi istatistiği panelin genelini ifade etmektedir ve aşă̆ıdaki gibi elde edilmektedir:

$$
\text { CIPS }=\frac{\sum_{t=1}^{n} C A D F_{t}}{N}
$$

Kullanılan üç değişken için CADF testi bulguları Tablo 2, 3 ve 4'te verilmiştir: 
Karabiyik, C., Dilber, I. / Journal of Yasar University, 2016, 11/44, 316-325

Tablo 2: GINI Değişkeni CADF Test Sonuçları

\begin{tabular}{|ll|ll|lll|ll|ll|}
\hline Avusturya & $-4.85 * * *$ & Danimarka & $-3.72 * *$ & İlanda & $-3.59 * *$ & Malavi & $-5.17 * * *$ & Portekiz & $-3.82 * *$ \\
\hline Belçika & $-3.97 * * *$ & Ekvador & $-4.64 * * *$ & İsrail & $-3.14 * *$ & Malezya & $-3.96 * *$ & Singapur & $-3.88 * *$ \\
\hline Bolivya & $-5.09 * * *$ & Misır & $-4.90 * * *$ & İtalya & $-3.63 * *$ & Malta & $-4.21 * *$ & Güney Afrika & $-3.44 * *$ \\
\hline Bulgaristan & $-4.07 * *$ & Fiji & $-5.35 * * *$ & Jamaika & $-4.99 * * *$ & Morityus & $-4.21 * *$ & İspanya & $-3.96 * *$ \\
\hline Kamerun & $-3.65 * *$ & Finlandiya & $-4.87 * * *$ & Japonya & $-4.01 * *$ & Meksika & $-4.36 * *$ & Sri Lanka & $-6.94 * * *$ \\
\hline Kanada & -2.73 & Fransa & $-4.29 * * *$ & Ürdün & $-5.26 * * *$ & Fas & $-3.51 * * *$ & Türkiye & $-3.16 *$ \\
\hline Şili & $-4.07 * *$ & Yunanistan & $-5.20 * * *$ & Kenya & $-4.41 * * *$ & Hollanda & $-4.11 * * *$ & İngiltere & $-4.18 * * *$ \\
\hline Çin & $-3.94 * *$ & Macaristan & $-6.70 * * *$ & Kore & $-3.02 * *$ & Norveç & $-3.93 * *$ & Tanzanya & $-6.38 * * *$ \\
\hline Kolombiya & $-3.82 * *$ & Hindistan & $-4.97 * * *$ & Kuveyt & $-3.48 * *$ & Filipinler & $-3.23 *$ & ABD & $-4.26 * * *$ \\
\hline Kibris & $-4.41 * * *$ & İran & $-3.58 * *$ & Lüksemburg & $-5.64 * * *$ & Polonya & $-3.63 * * *$ & Uruguay & $-5.51 * * *$ \\
\hline
\end{tabular}

CIPS-istatistiği $-4.32 * * *$

***,** ve * sirasıyla $\% 1, \% 5$ ve $\% 10$ anlamlılık düzeyinde anlamlı olarak ifade edilmektedir.

Tablo 3: FDI Değişkeni CADF Test Sonuçları

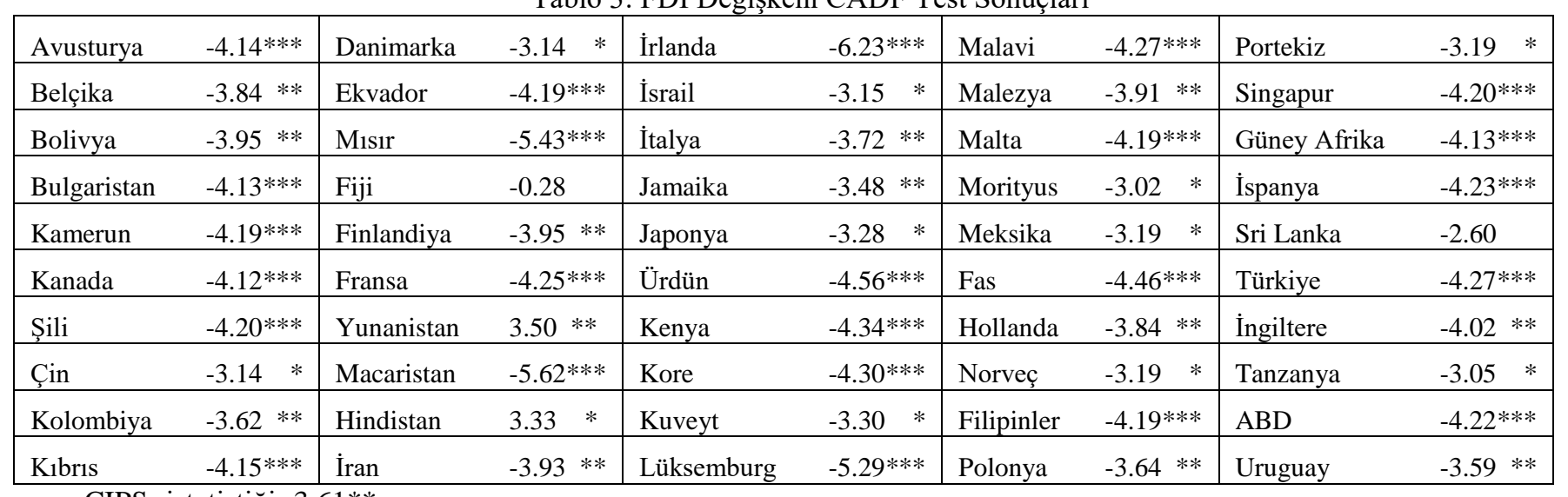

CIPS- istatistiği $-3.61 * *$

***,** ve * sirasıyla $\% 1, \% 5$ ve $\% 10$ anlamlılık düzeyinde anlamlı olarak ifade edilmektedir.

Tablo 4: GDP Değişkeni CADF Test Sonuçları

\begin{tabular}{|ll|ll|lll|ll|ll|}
\hline Avusturya & -1.27 & Danimarka & $-4.84 * * *$ & İrlanda & $-3.42 * *$ & Malavi & $-6.99 * * *$ & Portekiz \\
\hline Belçika & $-4.05 * *$ & Ekvador & -2.93 & İsrail & $-3.71 * *$ & Malezya & -3.05 & $*$ & Singapur & $-3.93 * *$ \\
\hline Bolivya & $-4.64 * *$ & Misır & $-4.45 * * *$ & İtalya & $-3.35 * *$ & Malta & -3.25 & $*$ & Güney Afrika & $-4.71 * * *$ \\
\hline Bulgaristan & $-4.69 * * *$ & Fiji & -2.01 & Jamaika & $-3.26 *$ & Morityus & $-4.47 * * *$ & İspanya & -1.94 \\
\hline Kamerun & $-4.06 * *$ & Finlandiya & $-3.60 * *$ & Japonya & $-4.03 * *$ & Meksika & $-5.05 * * *$ & Sri Lanka & -2.18 \\
\hline Kanada & $-4.44 * *$ & Fransa & $-3.45 * *$ & Ürdün & -2.48 & Fas & $-4.85 * * *$ & Türkiye & $-3.38 * *$ \\
\hline Şili & $-3.68 * *$ & Yunanistan & $-3.76 * *$ & Kenya & $-3.45 * *$ & Hollanda & -2.93 & İngiltere & $-6.15 * * *$ \\
\hline Çin & $-3.18 * *$ & Macaristan & $-4.89 * * *$ & Kore & $-7.60 * * *$ & Norveç & -3.05 & $*$ & Tanzanya & $-4.14 * * *$ \\
\hline Kolombiya & $-3.89 * *$ & Hindistan & $-4.42 * * *$ & Kuveyt & $-2.97 * *$ & Filipinler & $-4.64 * * *$ & ABD & $-4.23 * * *$ \\
\hline Kibris & $-3.85 * *$ & İran & $-4.50 * * *$ & Lüksemburg & $-4.19 * * *$ & Polonya & -2.80 & Uruguay \\
\hline
\end{tabular}

CIPS-istatistiği $-3.85^{* *}$

$* * *, * *$ ve * sirasıyla $\% 1, \% 5$ ve $\% 10$ anlamlılık düzeyinde anlamlı olarak ifade edilmektedir.

CADF birim kök testi sonuçlarına göre panelin genelini ifade eden CIPS istatistikleri incelendiğinde her üç değişkenin de $\% 5$ anlamlılık düzeyinde durağan oldukları görülmektedir. Tüm bu değişkenler düzey değerleri ile kullanılabilmektedirler. Test sonuçları yatay kesitler için ayrı ayrı incelendiğinde ise GINI değişkeni için sadece Kanada, 
FDI değişkeni için Fiji ve Sri Lanka son olarak GDP değişkeni için ise Avusturya, Ekvador, Fiji, Ürdün, Hollanda, Polonya, İspanya ve Sri Lanka'nın birim köke sahip olduğu görülmektedir.

YKB'nin varlığı durumunda ülkelere gelen şoklar yayılarak diğer ekonomilere sıçrayacaktır. Ayrıca hükümetler politika geliştirme sürecinde diğer hükümetlerin yürürlüğe koydukları politikaları da dikkate almak durumunda kalacaklardır. Benzer sebeplerle, YKB ampirik analiz sürecinde de hatalı sonuçlardan kaçınmak amacıyla dikkate alınmalıdır. Bu çalışmada, YKB'yi asimptotik olarak elimine etmek için Pesaran (2006) tarafindan geliştirilen ve YKB'yi dikkate alan Common Correlated Effects (CCE) tahmincisi kullanılmıştır. CCE tahmincisi $\mathrm{N}>\mathrm{T}$ ve $\mathrm{N}<\mathrm{T}$ durumlarının her ikisinde de regresyondaki eğim katsayısının yatay kesitlere göre farklılık göstermesine izin vererek etkin sonuçlar sunabilmektedir. CCE tahmincisi muhtemel olarak gözlemlenemeyen ortak faktörlerden kaynaklanmakta olan yatay kesit bağımlılığını, bağımlı ve bağımsız değişkenlerin yatay kesit ortalamalarını gözlemlenemeyen ortak faktörler için vekil değişken olarak atanması suretiyle dikkate alarak daha etkin analiz sonuçları vermektedir. Ayrıca, bağımsız değişkenler ile ortak faktörler arasında korelasyon olduğu durumda dahi CCE tahmincisi etkin olabilmektedir. CCE tahmincisinin kullandığg regresyon denklemi aşağıdaki heterojen panel modelinde gösterilmektedir:

$$
\begin{gathered}
y_{i t}=\alpha_{i}^{\prime} d_{t}+\beta_{i}^{\prime} x_{i t}+\varepsilon_{i t} \\
\varepsilon_{i t}=\gamma_{i}^{\prime} f_{i}+\varepsilon_{i t}
\end{gathered}
$$

Denklem 9'de yer alan " $\mathrm{d}_{\mathrm{t}}$ "değişkeni gözlemlenebilen sabit, trend, mevsimsel etki gibi deterministik unsurları göstermektedir. " $\mathrm{f}_{\mathrm{t}}^{\text {" }}$ değişkeni ise gözlemlenemeyen faktörleri temsilen denklemde bulunmaktadır. Panelin genelinin yorumlanmasında kullanlan CCEP (Common Correlated Effects Pooled) istatistiği aşağıdaki denklemde gösterildiği şekilde elde edilmektedir:

$$
\hat{b}_{p}=\left(\sum_{i=1}^{N} \theta X_{i}^{\prime} \bar{M}_{w} X_{i}\right)^{-1} \sum_{i=1}^{N} \theta_{i} X_{i}^{\prime} \bar{M}_{w} y_{i}
$$

$\mathrm{Bu}$ araştırmada kullanılmış olan veri seti için CCE tahmincisinin etkinliği daha yüksek olsa da analiz bulgularında hem CCE hem de En Küçük Kareler (EKK) tahmincisi sonuçları literatürdeki diğer çalışmalarla karşılaştırılabilmesi bakımından bir arada sunulacaktır. EKK ve CCE regresyon sonuçları Tablo 5'te raporlanmıştır:

Tablo 5: Regresyon Analizi Sonuçları

\begin{tabular}{|l|c|c|l|l|l|l|l|}
\hline \multicolumn{4}{|c|}{ CCE Tahmincisi } & \multicolumn{4}{c|}{ EKK Tahmincisi } \\
\hline Değişken & Katsay1 & Standart Sapma & Olasılık & Değişken & Katsay1 & Standart Sapma & Olasılık \\
\hline C & $-51,2373$ & 21,216 & $0,02^{* *}$ & C & 34,8289 & 1,45123 & $0,00^{* * *}$ \\
\hline FDI & $-0,00185$ & 0,0010 & $0,08^{*}$ & FDI & $-0,00004$ & 0,00001 & $0,00^{* * *}$ \\
\hline GDP & 3,58218 & 2,0113 & $0,07^{*}$ & GDP & 0,54151 & 0,12228 & $0,00^{* * *}$ \\
\hline
\end{tabular}

***,** ve * sirasıyla $\% 1, \% 5$ ve $\% 10$ anlamlılık düzeyinde anlamlı olarak ifade edilmektedir.

Her iki tahminciden elde edilen sonuçlara göre de gelir dağılımı eşitsizliği ile doğrudan yabancı sermaye yatırımları arasında negatif yönlü ilişki mevcuttur. Dış ülkelerden gerçekleştirilen bir birimlik doğrudan sermaye yatırımı Gini Katsayısı'nın -0,00185 birim azalmasına, bir başka deyişle daha adil bir gelir dağılımına olanak sağlamaktadır. Elde edilen bulgular Chıntrakarn vd. (2012); Doğan vd. (2013); Erkal vd. (2015); Jensen ve Rosas (2007); Ucal (2014) ile uyumluluk göstermektedir. Diğer yandan, hem CCE hem de EKK tahmincilerine göre Gini Katsayısı ile GSYİH arasında güçlü pozitif ilişki mevcuttur. CCE tahmincisi sonuçlarına göre, gayri safi yurtiçi hasılada gerçekleşecek olan bir birimlik artı̧̧ Gini katsayısında yaklaşık olarak 3,58 birimlik bir artışa sebep olacaktır. Bir başka ifadeyle, milli gelir attırılabilse dahi daha adil bir bölüşüm gerçekleşememektedir.

\section{Sonuç}

$\mathrm{Bu}$ araştırmada doğrudan yabancı sermaye yatırımlarının gelir dağılımı eşitsizliği üzerindeki etkileri farklı ekonomik yapıdaki az gelişmiş, gelişmekte olan ve gelişmiş 50 ülkeye ait verilerle 1970-2008 dönemi için panel veri analizi metodu kullanılarak incelenmiştir. Yapılan ampirik analizde, bağımlılık kuramını destekleyebilecek hiçbir bulguya rastlanmamış olup, doğrudan yabancı sermaye yatırımlarının gelir dağılımı eşitliği üzerinde negatif yönde etkisi olduğu sonucuna ulaşılmıştır. Bu bağlamda, doğrudan yabancı sermaye yatırımlarının teknoloji transferi, bilgi transferi, sermaye kıtlığının önüne geçilmesi gibi pek çok avantajıyla daha adil bir bölüşüme olanak sağlayabileceği öne sürülebilir. Doğrudan yabanc1 sermaye yatırımları ile gelir dağılımı eşitsizliği arasındaki ilişkinin pozitif yönde olmaması dahi yabancı yatırımların ekonomiye çekilmesi için yeni politikalar geliştirilmesine teşvik edici nitelik taşımaktadır. Hükümetler özellikle emek yoğun sektörlerde doğrudan yabancı sermaye yatırımları için uygun zemin oluşturabilirlerse, artan istihdam vasıtasıyla daha adil bir gelir dağılımı gerçekleşebilecek ve daha yüksek bir sermaye stoku ile ekonomik büyüme oranları yükselebilecektir. Ancak ampirik analiz sonuçlarına göre GSYİH ile gelir dağılımı eşitsizliği arasında gözlemlenen pozitif yönlü ilişki, artan milli gelirin halka eşit bir şekilde dağıtılamadığını işaret etmektedir. Son 20 yılda yükselen küreselleşme ve teknolojik değişimle beraber gelir dağılımı eşitsizliği de artma eğilimindedir. İlerleyen dönemlerde gelirin daha adil bölüşülebilmesi 
Karabiyik, C., Dilber, I. / Journal of Yasar University, 2016, 11/44, 316-325

için hükümetler doğrudan yabancı sermaye yatırımlarındaki düzenlemelerden ziyade gelir dağılımını düzeltici istihdam, eğitim, insan hakları ve özelliklede vergilendirme politikaları düzenlemeli ve yürürlüğe koymalıdır. 


\section{KAYNAKÇA}

Aitken, Brian, Ann Harrison, and Robert E. Lipsey. 1996. "Wages and Foreign Ownership A Comparative Study of Mexico, Venezuela, and the United States." Journal of International Economics 40 (3-4): 345-71. doi:10.1016/00221996(95)01410-1.

Baltagi, Badi. 2005. Econometric Analysis of Panel Data. Third Edit. John Wiley \& Sons Press.

Basu, Parantap, and Alessandra Guariglia. 2007. "Foreign Direct Investment, Inequality, and Growth." Journal of Macroeconomics 29 (4): 824-39. doi:10.1016/j.jmacro.2006.02.004.

Breusch, T S, and A R Pagan. 1980. "Lagrange Multiplier Test and to Model Applications Specification in Econometrics." Review of Economic Studies 47 (1): 239-53. doi:10.2307/2297111.

CHINTRAKARN, PANDEJ, DIERK HERZER, and PETER NUNNENKAMP. 2012. "Fdi and Income Inequality: Evidence From a Panel of U.S. States.” Economic Inquiry 50 (3): 788-801. doi:10.1111/j.1465-7295.2011.00384.x.

Crenshaw, Edward. 1992. "Cross-National Determinnts of Income Inequality: A Replication and Extension Using Ecological-Evolutionay Theory.” Social Forces 71 (2): 339-63.

Doğan, Ebül Muhsin, Ali Shahınpour, and Khadijeh Aghapour. 2013. “İran’ Da Gelir Dağılımı Üzerine Doğrudan Yabancı Yatırımın Etkisi.” Atatürk Üniversitesi Sosyal Bilimler Enstitüsü Dergisi 17 (3): 377-88.

Elveren, Adem Yavuz. 2013. "Gelir Dağılımı Çalışmaları İçin Bir Alternatif: Texas Üniversitesi Eşitsizlik Projesi Veri Setleri." Anadolu Üniversitesi Sosyal Bilimler Dergisi 13 (2): 35-42.

Erkal, Gökhan, Merter Akıncı, and Ömer Yılmaz. 2015. "Yoksulluk, Gelir Eşitsizliği ve Ekonomik Büyüme İlişkisi : Seçilmiş Doğu Avrupa ve Latin Amerika Ülkeleri İçin Ampirik Bir Analiz.” TISK Academy/TISK Akademi 10 (19): 66-87.

Feenstra, Robert C, and Gordon H Hanson. 1997. “Foreign Direct Investment and Relative Wages: Evidence from Mexico’s Maquiladoras." Journal of International Economics 42 (3-4): 371-93. doi:10.1016/S0022-1996(96)01475-4.

Figini, Paolo, and Holger Görg. 2011. "Does Foreign Direct Investment Affect Wage Inequality? An Empirical Investigation.” World Economy 34 (9): 1455-75. doi:10.1111/j.1467-9701.2011.01397.x.

Gedikli, Ayfer. 2011. "Çok Uluslu Şirketler Ve Doğrudan Yabancı Yatırımların Gelişmekte Olan Ülkelerin Kalkınması Üzerine Etkileri.” Girişimcilik ve Kalkınma Dergisii 6 (1): 96-146.

Gökalp, M Faysal, Ercan Baldemir, and Gonca Akgün. 2011. "Türkiye Ekonomisinde Dışa Açılma ve Gelir Eşitsizlikleri İlişkisi." YÖNETIM VE EKONOMI 18 (1): 87-104.

Gujarati, Damodar N. 2009. Basic Econometrics. New York: McGraw-Hill Education.

Herzer, Dierk, and Peter Nunnenkamp. 2011. "FDI and Income Inequality: Evidence from Europe." Kiel Working Paper No. 1675. http://dspace.cigilibrary.org/jspui/handle/123456789/31393.

Jensen, Nathan M., and Guillermo Rosas. 2007. "Foreign Direct Investment and Income Inequality in Mexico, 19902000.” International Organization 61 (3): 467-87. doi:10.1017/S0020818307070178.

Mah, Jai S. 2002. "The Impact of Globalization on Income Distribution: The Korean Experience.” Applied Economics Letters 9 (15): 1007-9. doi:10.1080/13504850210149124.

Negishi, Takashi. 2014. Developments of International Trade Theory. 2nd ed. Vol. Second enh. Springer International Publishing. http://ezproxy.eafit.edu.co/login?url=http://search.ebscohost.com/login.aspx?direct=true $\& d b=e d s e b k \& A N=1073836$ \&lang=es\&site=eds-live.

Ongan, Tevfik Hakan. 2004. “Gelir Eşitsizliği, Doğrudan Yabancı Sermaye Yatırımları ve Ters U Eğrisi.” İktisat Fakültesi Mecmuası 54 (1): 153-65.

Pesaran, M. Hashem. 2006. "Estimation and Inference in Large Heterogeneous Panels with Cross Section Dependence." Econometrica 74 (4): 967-1012. doi:10.1111/j.1468-0262.2006.00692.x.

Pesaran, M Hashem. 2004. “General Diagnostic Tests for Cross Section Dependence in Panels.” SSRN Electronic Journal 1229 (August).

. 2007. "A Simple Panel Unit Root Test in the Presence of Cross-section Dependence." Journal of Applied Econometrics 22 (2): 265-312. doi:10.1002/jae.

Protsenko, A. 2004. "Vertical and Horizontal Foreign Direct Investments in Transition Countries."

Rodrik, Dani. 1997. “Has Globalization Gone Too Far?” California Management Review 39 (3): $29-53$. doi:10.2307/41165897.

Sarisoy, Idris, and Selcuk Koc. 2012. "The Effect of Foreign Direct Investment on Poverty : Panel Regression Analysis for 40 Selected Underdeveloped and Developing Countries.” Ç. Ü. Sosyal Bilimler Enstitüsü Dergisi 21 (3): $225-40$.

Seyrek, İsmail. 2002. "Küreselleşme Sürecinde İktisat Politikaları ve Yakınsama Tezi." G. Ü. İBF Dergisi 4 (2): 1-21.

Stolper, Wolfgang F., and Paul A Samuelson. 1941. "Protection and Real Wages." Review of Economic Studies 9 (1): 5873.

Sylwester, Kevin. 2005. "Foreign Direct Investment, Growth and Income Inequality in Less Developed Countries." 
International Review of Applied Economics 19 (3): 289-300. doi:10.1080/02692170500119748.

Tsai, Pan-Long. 1995. "Foreign Direct Investment and Income Inequality: Further Evidence." World Development 23 (3): 469-83. doi:10.1016/0305-750X(95)00136-Z.

Ucal, Meltem Şengün. 2014. "Panel Data Analysis of Foreign Direct Investment and Poverty from the Perspective of

Developing Countries." Procedia - Social and Behavioral Sciences 109: 1101-5. doi:10.1016/j.sbspro.2013.12.594.

UTIP, University of Texas Inequality Project, http:// utip.gov.utexas.edu/ 